\title{
VATS lobectomy outcomes in octogenarian patients: a retrospective series
}

\author{
William Grossi ${ }^{1}$, Alice Bellini' ${ }^{2}$, Francesco Londero ${ }^{1}$, Gianluca Masullo ${ }^{1}$, Angelo Morelli ${ }^{1}$ \\ ${ }^{1}$ Department of Cardiothoracic Surgery, Thoracic Surgery Unit, Santa Maria della Misericordia Hospital, Udine, Italy; ${ }^{2}$ Department of Cardiac, \\ Thoracic, Vascular Sciences and Public Health, Thoracic Surgery Unit, University of Padova, Padova, PD, Italy \\ Correspondence to: William Grossi. Cardiothoracic Department, Piazzale Santa Maria della Misericordia, Udine 33100, Italy. \\ Email: chirurgiatoracica@asuiud.sanita.fvg.it; william.grossi@asuiud.sanita.fvg.it.
}

\begin{abstract}
The proportion of octogenarian patients is growing over years. Nowadays video-assisted thoracoscopic surgery (VATS) permits to treat old age patients, even with limited pulmonary function, not otherwise suitable for surgery. The aim of our study is to analyse the factors influencing short and long terms outcome of the octogenarian patients underwent VATS lobectomy. Between January 2013 and March 2019 we performed 292 VATS lobectomies of which 26 patients were octogenarian. The patients' population were divided in two groups according to patient's age (group 1: patient younger than 80 years old; group 2: older than 80 years old). The octogenarian patients had higher post-operative complication (POC) rate and hospital stay than the younger patients. Surgeon's learning curve was significantly associated to higher POC in both group of patients (group 1: $\mathrm{P}<0.002$, group 2: $\mathrm{P}<0.001$ ). Patients of both groups who underwent VATS lobectomy performed by resident surgeon supported by a skilled tutor had a significantly lower risk of POC (group 1 and group 2: $\mathrm{P}<0.001$ ). Right upper lobectomy was significantly associated to higher risk of $\mathrm{POC}$ in both groups [group 1: $\mathrm{P}<0.008$, relative risk $(\mathrm{RR})=1.7$ and group 2 : $\mathrm{P}<0.032, \mathrm{RR}=1.5$ ] whereas left lower lobectomy showed higher risk of POC only in group $1(\mathrm{P}<0.03, \mathrm{RR}=1.9)$. Hospital stay was significantly influenced by $\mathrm{POC}$ (group 1 : $\mathrm{P}<0.001$, group 2: $\mathrm{P}<0.03$ ) and by post-operative atrial fibrillation in octogenarian group $(\mathrm{P}<0.04)$. Overall survival was influenced by lung cancer's stage but not by age and POC in both groups. In conclusion octogenarian patients should undergo surgery after a completed preoperative assessment due to their comorbidities. Post-operative outcome and overall survival of elderly patients are comparable with younger patients.
\end{abstract}

Keywords: Video-assisted thoracoscopic surgery (VATS); lobectomy; octogenarian; elderly; outcome

Received: 28 November 2019; Accepted: 12 December 2019; Published: 25 May 2020.

doi: $10.21037 /$ ccts.2019.12.07

View this article at: http://dx.doi.org/10.21037/ccts.2019.12.07

\section{Introduction}

Giving the progressive aging of the population, the interest for octogenarian patients is increasing in the last decades (1). Today, octogenarians' life expectancy ranged from 5 to 9 years for men and from 5 to 10 years for women, respectively (2). In this scenario, elderly patients diagnosed with a resectable pulmonary neoplastic disease represent a clinical challenge for the physician. According to the recent literature, anatomic surgical resection should be offered with curative intent when feasible, anyhow octogenarians experienced increased periand post-operative complications and mortality compared to younger ones $(2,3)$, related to their frail status.

For this reason, careful patients selection and preoperative evaluation are needful (4), in order to propose pulmonary lobectomy only to this subgroup of fit elderly patients with good performance status, reserving other treatment options, including stereotactic body radiation therapy (SBRT) to patients in poor general conditions or unwilling to undergo surgery (5).

In recent years, the advent of video-assisted thoracic surgery (VATS) resulted effective in decreasing the peri- and post-operative morbidity, compared to open thoracotomy, 
with similar oncological outcomes (6). Moreover, patients with limited pulmonary function have better outcomes when VATS approach is adopted (7).

Several Authors analyzed elderly population in terms of risk factors for post-operative complications and affecting survival (3,8-11), type of surgical approach (VATS vs. open) $(2,6,12-14)$ and type of resection (lobar vs. sublobar) (15), but to the best of our knowledge no previous comparison between elderly ( $>80$ years) and young $(<80$ years) patients underwent VATS lobectomy is reported in literature.

The aim of our study is to analyze the factors influencing short (post-operative complications and hospital stay) and long term (overall survival) outcomes of the octogenarian patients underwent VATS lobectomy.

\section{Methods}

We retrospectively reviewed our surgical case history of all patients subjected to VATS lobectomy from January 2013 and March 2019. Data was collected using the hospital's database (G2 software) and medical records for missing data. Apple Numbers 6.0 and SPSS 24.0 were the software used to manage the data. Fisher's exact test or chi-square comparison were the statistical tests employed. The univariate and multivariate statistical analysis were carried out with Cox regression test with the purpose to individuate the variables determining differences between octogenarian patients and the younger patients. All $\mathrm{P}$ values lower than 0.05 were considered statistically significant. Patient population was divided in two groups: group 1 and group 2. This latter was represented by octogenarian patients (>80 years old), whereas group 1 included younger patients ( $<80$ years old). The exclusion criteria were: open lobectomy and open and VATS sublobar resections. All the patients underwent VATS lobectomy, including cases of conversion, were included in the study. According to selection criteria we collected 292 VATS lobectomies of which 26 (8.9\%) in octogenarian patients. Several variables were analysed in group 1 and 2: age at surgery, type of lobectomy, operating time, post-operative complications, resident surgeon and learning curve, oncological stage, hospital stay and overall survival. Basically we analysed the differences between the two groups of patients in terms of post-operative complication (POC), hospital stay and overall survival in order to identify possible risk factors.

The study was conducted in accordance with the declaration of Helsinki (as revised in 2013). The institutional ethical approval and informed consent were waived.

\section{Results}

Thirty-three cases were converted in group 1 (conversion rate of $12.4 \%$ ), five cases in group 2 (conversion rate of $19.2 \%)$. POC in group 1 were $111(41.7 \%)$ and fifteen in group $2(57.7 \%)$. According to literature we set four days as cut-off for longer hospital stay (16). This latter was longer in group 2 than group 1 respectively by $76.9 \%$ (20 cases) and by $58.3 \%$ (155 cases). There were no significant differences between the two groups in terms of operating time average (group 1: $216.5 \mathrm{~min}$, range 110 $430 \mathrm{~min}$;. group 2: $211.2 \mathrm{~min}$, range $110-320 \mathrm{~min}$ ). There were no major differences between group 1 and 2 in terms of type of lobectomy distribution: right upper lobectomy (RUL) 80 cases $(30.1 \%)$ in group 1 and 7 cases $(26.9 \%)$, middle lobectomy (ML) 27 cases (10.2\%) in group 1 and 3 cases $(11.5 \%)$ in group 2, right lower lobectomy (RLL) 49 cases $(18.4 \%)$ in group 1 and 6 cases $(23.1 \%)$ in group 2, left upper lobectomy (LUL) 60 cases (22.6\%) in group 1 and 7 cases (26.9\%), left lower lobectomy (LLL) 53 cases (19.9\%) in group 1 and 4 cases (15.4\%). Stage I was more frequent in group 2 than group 1 respectively by $84.6 \%$ (22 cases) and by $64.3 \%$ (171 cases), whereas stage IIIa occurred in one case $(3.8 \%)$ in group 2 and in fifty-eight cases $(21.8 \%)$ in group 1 (Table 1 ). The main differences between the two group of patients were the POC and hospital stay. Based on this evidence, we performed an univariate analysis with the aim to identify the possible risk factors responsible of this significant difference. The variables significantly related to POC occurrence were: learning curve, RUL, resident surgeon and LLL. Surgeon's learning curve [group 1: $\mathrm{P}<0.002, \mathrm{RR}=2$ and group 2: $\mathrm{P}<0.001, \mathrm{RR}=2.3$ ] and RUL (group 1 : $\mathrm{P}<0.008$, $\mathrm{RR}=1.7$; group 2: $\mathrm{P}<0.032, \mathrm{RR}=1.5$ ) were associated to higher risk of POC in both groups. If VATS lobectomy was performed by a resident supervised by a skilled surgeon, the risk of POC was halved in both group of patients (group 1: $\mathrm{P}<0.001$, relative risk $(\mathrm{RR})=0.4$; group 2 : $\mathrm{P}<0.001$, $\mathrm{RR}$ $=0.4)$. LLL was significantly associated with higher POC rate in group $1(\mathrm{P}<0.03, \mathrm{RR}=1.9)$ but not in group $2(\mathrm{P}<0.09$, $\mathrm{RR}=1.6)$. The multivariate statistical analysis resulted significant $(\mathrm{P}<0.001)$ in terms of learning curve (group 1: $\mathrm{P}<0.003, \mathrm{RR}=1.9$; group 2: $\mathrm{P}<0.001, \mathrm{RR}=2.3$ ) and $\mathrm{RUL}$ (group 1: $\mathrm{P}<0.015, \mathrm{RR}=1.6$; group 2: $\mathrm{P}<0.018, \mathrm{RR}=1.6$ ) (Figures 1,2). Regarding hospital stay, the univariate analysis individuated several variables to be significantly: POC 
Table 1 Patient characteristics

\begin{tabular}{|c|c|c|c|c|}
\hline Variables & \multicolumn{2}{|c|}{ Age $<80$} & \multicolumn{2}{|c|}{ Age $>80$} \\
\hline Men & 161 & 60.5 & 14 & 53.8 \\
\hline Women & 105 & 39.5 & 12 & 46.2 \\
\hline VATS lobectomy & 266 & 91.1 & 26 & 8.9 \\
\hline Learning curve & 114 & 42.9 & 10 & 38.5 \\
\hline Uniport & 61 & 22.9 & 1 & 3.8 \\
\hline Biportal & 197 & 74.1 & 22 & 84.6 \\
\hline Multiport & 34 & 12.8 & 3 & 11.5 \\
\hline Hospital stay $>4$ days & 155 & 58.3 & 20 & 76.9 \\
\hline Median hospital stay (days) & 6 & $(1-25)$ & 7 & $(3-19)$ \\
\hline Median operating time (min) & 216.5 & $(110-430)$ & 211.2 & $(110-320)$ \\
\hline RUL & 80 & 30.1 & 7 & 26.9 \\
\hline ML & 27 & 10.2 & 3 & 11.5 \\
\hline RLL & 49 & 18.4 & 6 & 23.1 \\
\hline LUL & 60 & 22.6 & 7 & 26.9 \\
\hline LLL & 53 & 19.9 & 4 & 15.4 \\
\hline
\end{tabular}

VATS, video-assisted thoracoscopic surgery; POC, post-operative complication; PUL, right upper lobectomy; ML, middle lobectomy; RLL, right lower lobectomy; LUL, left upper lobectomy; LLL, left lower lobectomy.

(group 1: $\mathrm{P}<0.001, \mathrm{RR}=4.7$ and group 2: $\mathrm{P}<0.02, \mathrm{RR}=3.1$ ) air leak (group1: $\mathrm{P}<0.001, \mathrm{RR}=2.7$ and group 2: $\mathrm{P}<0.06$, $\mathrm{RR}=3$ ) atrial fibrillation (group $1: \mathrm{P}<0.04, \mathrm{RR}=1.6$ and group 2: $\mathrm{P}<0.03, \mathrm{RR}=1.9$ ) RUL (group 1: $\mathrm{P}<0.04, \mathrm{RR}=1.5$ and group 2: $\mathrm{P}<0.18$ ) and emergency reoperation (group 1: $\mathrm{P}<0.013, \mathrm{RR}=2.6$ and group $2: \mathrm{P}<0.38$ ). In the multivariate analysis was statistically significant $(\mathrm{P}<0.001)$ in terms of POC in both group (group 1: $\mathrm{P}<0.001, \mathrm{RR}=4.5$ and group 2: $\mathrm{P}<0.03, \mathrm{RR}=3.5)$ and atrial fibrillation in group $2(\mathrm{P}<0.04$, $\mathrm{RR}=2$ ). Kaplan-Meyer was utilised to analyse overall survival of group 1 and group 2 considering POC, age and stage as variables. Based on this analysis, there were no significantly differences of overall survival between group 1 and 2 in terms of POC ( $\log$ rank Mantel-cox $P=0.07)$ and age $(\log$ rank Mantel-cox $\mathrm{P}=0.168)$. Oncological stage determined statistically differences in terms of overall survival regardless of patient's group (Figure 3; Log Rank Mantel-cox $\mathrm{P}=0.001$ ).

\section{Discussion}

Recent Italian Statistic National Institute's report (Istat) (1) 


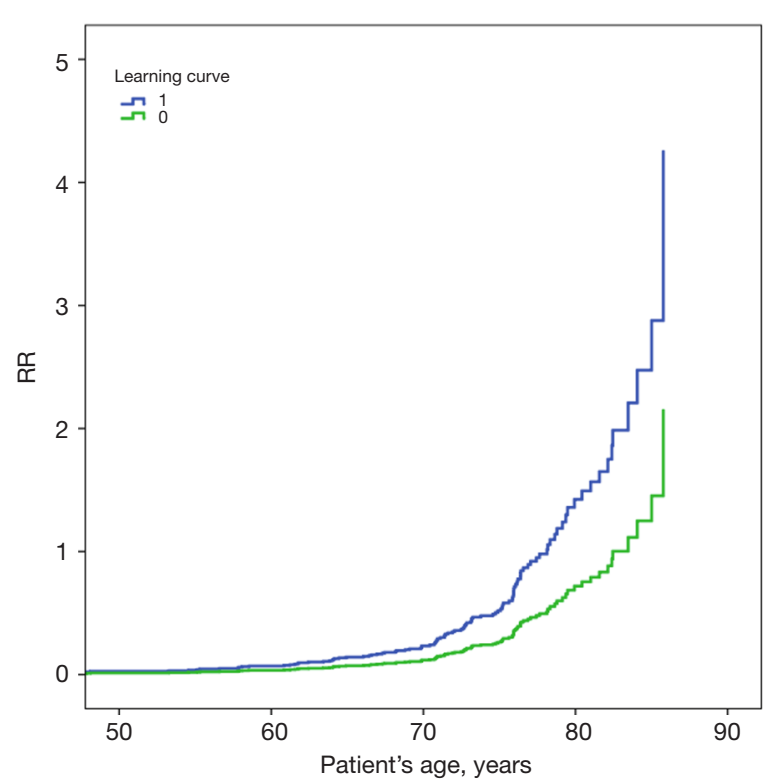

Figure 1 Risk curve associated to surgeon's learning curve related to patient's age. $\mathrm{RR}$, relative risk.

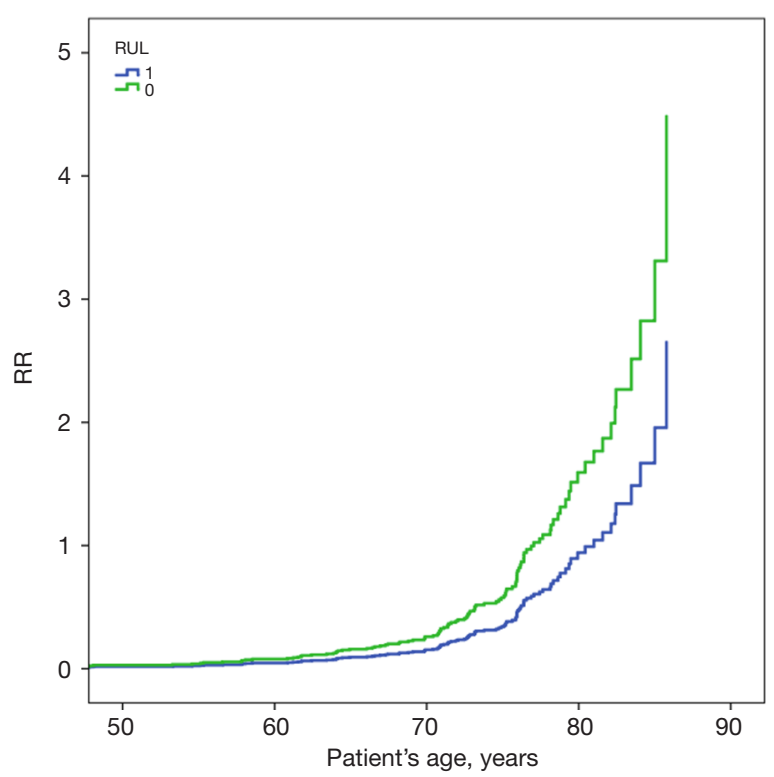

Figure 2 Risk curve of patients underwent RUL. RR, relative risk; RUL, right upper lobectomy.

shows that the proportion of elderly population is increased in the last decade and it is expected to further grow in the future. Currently $19.2 \%$ of the Italian population is between 65 and 84 years old and 3.6\% is more than 85 years old (1). According to octogenarians life expectancy

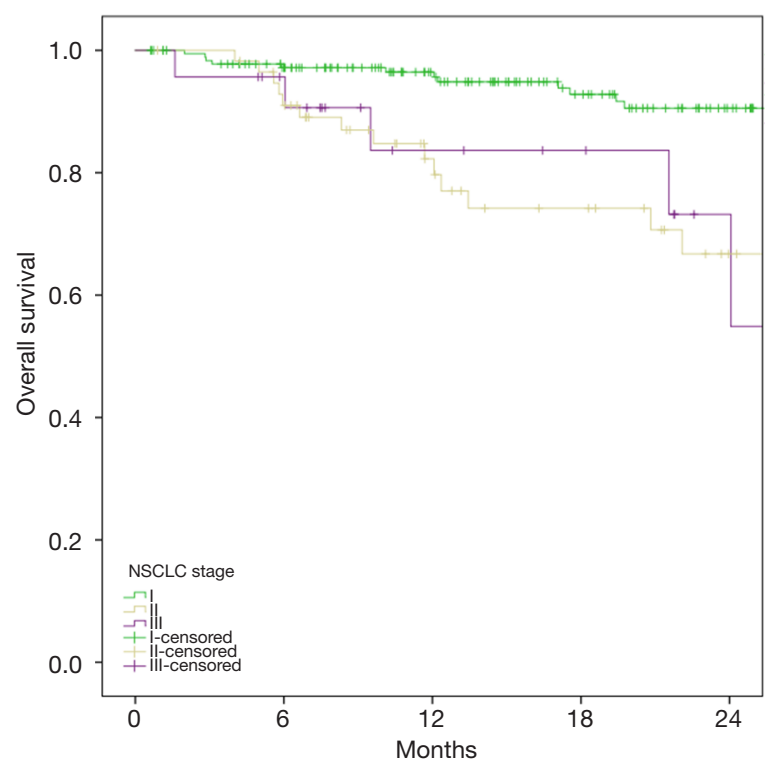

Figure 3 Overall survival according to oncological stage. NSCLC, non-small cell lung cancer.

(approximately 5-10 years) it is necessary to re-consider assumptions about oncological care of the elderly. Based on these evidences NSCLC early stage in octogenarian patients should be considered for radical surgical treatment possibly with mini-invasive approach (VATS or Robotic) barring any significant risk factor. In fact, Sarkaria et al. (2) evaluated postoperative outcome of octogenarian patients compared different surgical approach (open, robotic and VATS). In this large series of 1,849 patients, as already confirmed in previous studies (12), validated the miniinvasive surgery superiority in confront with open approach in terms of post-operative complications and hospital stay (2). Other series (6) confirm that minimally invasive surgery represent the treatment of choice in this higher risk patient population. Several retrospective reviews concluded that elderly patients with higher risk and poor pulmonary function have better outcome if VATS is adopted and have similar post-operative complication rate of those with normal pulmonary function (7). Based on evidence demonstrating how VATS is more effective than open approach in terms of post-operative outcome and overall survival, we considered meaningless comparing VATS with open surgery. Instead, we focus our interest on octogenarian patients subjected to VATS lobectomy demonstrating comparable outcomes and overall survival with younger patients. Moreover, another interest aspect of the VATS scenario is the recent development 
of VATS sublobar resection (wide wedge resection and anatomical segmentectomy). Zhang et al. (15) conducted a multicenter retrospective study in which 1,579 patients were selected, with the aim to compare perioperative outcomes and survival of sublobar resections $v s$. lobectomy in patients older than 65 years old. As evaluated by other authors previously $(17,18)$, they concluded that sublobar resection was associated with significantly better perioperative outcome in elderly patients with clinical stage I NSCLC (8). Further to that, there is evidence suggesting that VATS sublobar resections have comparable overall survival of VATS lobectomies in stage I NSCLC, but more randomised studies are needed to validate it. Based on heterogeneous outcomes between patients operated with lobectomy and segmentectomy according to the different oncologic stages and lymphadenectomy, in our study we decided to enrol only those patients underwent VATS lobectomy with the aim to collect more accurate data in terms of overall survival and perioperative outcome $(19,20)$. In our institute the VATS lobectomy training program involved the residents too. In fact, after the Consultant learning curve was completed, the residents begin to learn this technique obtaining results in terms of conversion rate and post-operative outcome comparable with those of senior surgeons $(21,22)$. Moreover, based on the data of this study, residents had lower rate post-operative complications than senior surgeons if they were in learning curve's phase. Probably this aspect is affected by a selection bias; patients operated by residents were accurately selected in terms of oncological stage (stage I), no adhesions, complete fissure, peripheral lesions and good preoperative pulmonary function. In our experience RLL, LLL and senior surgeon's learning curve were associate with higher post-operative complication rate. Therefore these factors should be considered for the patients pre-operative assessment with the purpose to stratify the patients population, especially if octogenarian, in terms of surgical risk.

\section{Conclusions}

Octogenarian patients are defined to be frail due to of their several comorbidities and they should undergo surgery after a complete and meticulous pre-operative assessment in order to determine the associated surgical risks. The VATS approach allows to treat elderly patients, even with reduction of pulmonary function, in order to lower rate of postoperative complication and quick functional recovery (7) with comparable outcome and survival. Based on our experience, learning curve and RUL are risk factors in terms of POC occurrence in both patients' groups. In the case of a resident surgeon learning curve, if helped by a skilled surgeon, there is no impact on POC, on the contrary it seems to reduce the risk of POC both in group 1 and in group 2. Longer hospital stay is significantly influenced by POC in both group and by atrial fibrillation in group 2. Moreover, there are no significant differences in terms of overall survival between the two groups. Oncological stage seems to be a negative prognostic factor in terms of overall survival independently from patient's age. Instead, patients age and POC do not impact on overall survival. In conclusion, there is strong evidence that elderly patients are characterised by proper biological and oncologic features. Based on this evidence, new branches of oncology are being developed, such as the so-called Onco-geriatric with the purpose of identifying tailored oncologic and surgical workup. Based on this background, additional research on the octogenarian population is needed. Moreover, considering the sublobar resections, nowadays there is not reliable data in terms of overall survival and free disease survival in the elderly patients, therefore a longer follow-up is needed.

\section{Acknowledgments}

Funding: None.

\section{Footnote}

Provenance and Peer Review: This article was commissioned by the Guest Editors (Francesco Zaraca, Reinhold Perkmann, Luca Bertolaccini and Roberto Crisci) for the series "Thoracic Surgery Without Borders" published in Current Challenges in Thoracic Surgery. The article has undergone external peer review.

Conflicts of Interest: All authors have completed the ICMJE uniform disclosure form (available at https://ccts. amegroups.com/article/view/10.21037/ccts.2019.12.07/ coif). The series "Thoracic Surgery Without Borders" was commissioned by the editorial office without any funding or sponsorship. The authors have no other conflicts of interest to declare.

Ethical Statement: The authors are accountable for all aspects of the work in ensuring that questions related to the accuracy or integrity of any part of the work are 
appropriately investigated and resolved. The study was conducted in accordance with the declaration of Helsinki (as revised in 2013). The institutional ethical approval and informed consent were waived.

Open Access Statement: This is an Open Access article distributed in accordance with the Creative Commons Attribution-NonCommercial-NoDerivs 4.0 International License (CC BY-NC-ND 4.0), which permits the noncommercial replication and distribution of the article with the strict proviso that no changes or edits are made and the original work is properly cited (including links to both the formal publication through the relevant DOI and the license). See: https://creativecommons.org/licenses/by-nc-nd/4.0/.

\section{References}

1. Indicatori demografici ISTAT. Stime per l'anno 2018. Report 7 febbraio 2019. Available online: www.istat.it

2. Sarkaria IS, Gorrepati ML, Mehendale S, et al. Lobectomy in octogenarians: real world outcomes for robotic-assisted, video-assisted thoracoscopic, and open approaches. J Thorac Dis 2019;11:2420-30.

3. Feczko A, McKeown E, Wilson JL, et al. Assessing survival and grading the severity of complications in octogenarians undergoing pulmonary lobectomy. Can Respir J 2017;2017:6294895.

4. Brunelli A, Kim AW, Berger KI, et al. Physiologic evaluation of the patient with lung cancer being considered for resectional surgery: diagnosis and management of lung cancer, 3rd ed: American College of Chest Physicians evidence-based clinical practice guidelines. Chest 2013;143:e166S-90S.

5. Abreu CE, Ferreira PP, de Moraes FY, et al. Stereotactic body radiotherapy in lung cancer: an update. J Bras Pneumol 2015;41:376-87.

6. Port JL, Mirza FM, Lee PC, et al. Lobectomy in octogenarians with non-small cell lung cancer: ramifications of increasing life expectancy and the benefits of minimally invasive surgery. Ann Thorac Surg 2011;92:1951-7.

7. Oparka J, Yan TD, Ryan E, et al. Does video-assisted thoracic surgery provide a safe alternative to conventional techniques in patients with limited pulmonary function who are otherwise suitable for lung resection? Interact Cardiovasc Thorac Surg 2013;17:159-62.

8. Dominguez-Ventura A, Cassivi SD, Allen MS, et al. Lung cancer in octogenarians: factors affecting long-term survival following resection. Eur J Cardiothorac Surg 2007;32:370-4.

9. Hino H, Murukawa T, Ichinose J, et al. Results of lung cancer surgery for octogenarians. Ann Thorac Cardiovasc Surg 2015;21:209-16.

10. Hino H, Karasaki T, Yoshida Y, et al. Risk factors for postoperative complications and long-term survival in lung cancer patients older than 80 years. Eur J Cardiothorac Surg 2018;53:980-6.

11. Hino H, Karasaki T, Yoshida Y, et al. Competing risk analysis in lung cancer patients over 80 years old undergoing surgery. World J Surg 2019;43:1857-66.

12. Cattaneo SM, Park BJ, Wilton AS, et al. Use of videoassisted thoracic surgery for lobectomy in the elderly results in fewer complications. Ann Thorac Surg 2008;85:231-5; discussion 235-6.

13. Igai $H$, Takahashi $M$, Ohata K, et al. Surgical treatment for non-small cell lung cancer in octogenarians - the usefulness of video-assisted thoracic surgery. Interact CardioVasc Thorac Surg 2009; 9:274-7.

14. Berry MF, Onaitis MW, Tong BC, et al. A model for morbidity after lung resection in octogenarians. Eur J Cardiothorac Surg 2011;39:989-94.

15. Zhang $Z$, Feng $\mathrm{H}$, Zhao H, et al. Sublobar resection is associated with better perioperative outcomes in elderly patients with clinical stage I non-small lung cancer: a multicenter retrospective cohort study. J Thorac Dis 2019;11:1838-48.

16. Batchelor TJP, Rasburn NJ, Abdelnour-Berchtold E, et al. Guidelines for enhanced recovery after lung surgery: recommendations of the Enhanced Recovery After Surgery (ERAS®) Society and the European Society of Thoracic Surgeons (ESTS). Eur J Cardiothorac Surg 2019;55:91-115.

17. Tsutani $Y$, Tsubokawa N, Ito M, et al. Postoperative complications and prognosis after lobar resection versus 30. sublobar resection in elderly patients with clinical Stage I non-small-cell lung cancer. Eur J Cardiothorac Surg 2018;53:366-71.

18. Nishio W, Yoshimura M, Maniwa Y, et al. Re-Assessment of Intentional Extended Segmentectomy for Clinical T1aN0 Non-Small Cell Lung Cancer. Ann Thorac Surg 2016;102:1702-10.

19. Altorki NK, Kamel MK, Narula N, et al. Anatomical segmentectomy and wedge resections are associated with comparable outcomes for small cT1N0 non-small cell lung cancer. J Thorac Oncol 2016;11:1984-92.

20. Zhao ZR, Situ DR, Lau RWH, et al. Comparison 
of Segmentectomy and Lobectomy in Stage IA Adenocarcinomas. J Thorac Oncol 2017;12:890-6.

21. Martin-Ucar AE, Aragon J, Bolufer Nadal S, et al. The influence of prior multiport experience on the learning curve for single-port thoracoscopic lobectomy: a multicentre comparative study $\dagger$. Eur J Cardiothorac Surg
2017;51:1183-7.

22. Reed MF, Lucia MW, Starnes SL, et al. Thoracoscopic lobectomy: introduction of a new technique into a thoracic surgery training program. J Thorac Cardiovasc Surg 2008;136:376-81. doi: $10.21037 /$ ccts.2019.12.07

Cite this article as: Grossi W, Bellini A, Londero F, Masullo G, Morelli A. VATS lobectomy outcomes in octogenarian patients: a retrospective series. Curr Chall Thorac Surg 2020;2:16. 